\title{
GROWTH AND CHACACTERIZATION BY X-RAY DIFFRACTION OF Ni(II)(L-GLUTAMINE) COMPLEX
}

\author{
Oliveira, R. M. S.*; Melo, E. B.; de Menezes, A. S. \\ Departamento de Física, CCET, Universidade Federal do Maranhão, São Luís, MA, Brazil \\ *raisamarya@gmail.com
}

\begin{abstract}
Most metal complex with amino acids have the metal ions coordinated to nitrogen and one of the carboxylate oxygen atoms of the amino acid group of two amino acid molecules, while the remaining carboxylate oxygen atoms are bonded to copper ions of neighboring molecules. However, a different situation can occurs where metal ions are coordinated to one amino acid molecule as in the compounds described above, and, in addition, are coordinated to the side chain carboxylate group or by the side chain amine of the other amino acid molecule. One of those

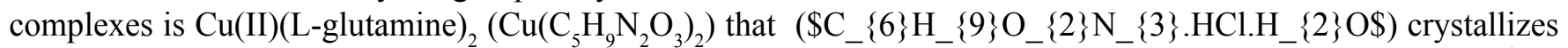
in the monoclinic structure with 4 molecules by unit cell, space group $\mathrm{C} 2$ and cell parameters $a=28.0610$ (5) $\AA, b$ $=5.0756(1) \AA, c=9.3719(2) \AA$ and $\beta=99.514(8)^{\circ}$. In this work, we used the nickel instead of cooper to grow the $\mathrm{Ni}(\mathrm{II})(\mathrm{L} \text {-glutamine) })_{2}$. In order to obtain this crystal, $1 \mathrm{~mol}$ of $\mathrm{NiCl}_{2} \cdot 6 \mathrm{H}_{2} \mathrm{O}$ was added to an aqueous solution with 2 mols of L-glutamine. $\mathrm{NaOH}$ was added to this solution to adjust the $\mathrm{pH}$. The solution was kept at $30^{\circ} \mathrm{C}$ to promote the evaporation of the solvent. After some days polycrystalline blue spheres has appeared and the size is dependent on $\mathrm{pH}$. X-ray powder diffraction measurements of the $\mathrm{Ni}(\mathrm{II})$ (L-glutamine) $)_{2}$ showed a pattern different from the $\mathrm{Cu}$ (II)(L-glutamine) ${ }_{2}$ crystal. A study as a function of the metal ion was performed in order to see the behavior of glutamine complex with different metal ions like $\mathrm{Co}(\mathrm{II}), \mathrm{Mn}(\mathrm{II})$ and $\mathrm{Cr}(\mathrm{II})$.

Financial support: CNPq and FAPEMA.
\end{abstract}

